\title{
Histoires du bleu
}

\section{Maurice Fréchuret}

\section{OpenEdition}

Journals

Édition électronique

URL : https://journals.openedition.org/critiquedart/2237

DOI : $10.4000 /$ critiquedart.2237

ISBN : 2265-9404

ISSN : 2265-9404

Éditeur

Groupement d'intérêt scientifique (GIS) Archives de la critique d'art

\section{Édition imprimée}

Date de publication : 1 avril 2001

ISBN : 1246-8258

ISSN : $1246-8258$

\section{Référence électronique}

Maurice Fréchuret, « Histoires du bleu », Critique d'art [En ligne], 17| Printemps 2001, mis en ligne le 01 mars 2012, consulté le 21 septembre 2021. URL : http://journals.openedition.org/critiquedart/2237 DOI : https://doi.org/10.4000/critiquedart.2237

Ce document a été généré automatiquement le 21 septembre 2021

Archives de la critique d'art 


\title{
Histoires du bleu
}

\author{
Maurice Fréchuret
}

\section{RÉFÉRENCE}

Jacquemin, Frédérique. Histoire du bleu, Paris : Noesis, 2000

Pastoureau, Michel. Bleu : histoire d'une couleur, Paris : Ed. du Seuil, 2000

1 Il est sans doute difficile d'affirmer que le bleu est, parmi toutes les couleurs, celle que les peintres affectionnent le plus mais il reste, chez les historiens, un objet d'analyse qui suscite depuis longtemps les interrogations et les commentaires les plus nombreux. Les récents ouvrages de Frédérique Jacquemin et de Michel Pastoureau en témoignent qui, de manière quasi simultanée, établissent tous deux une histoire du bleu et nous convient à appréhender la riche symbolique de cette couleur comme les multiples usages qui furent faits d'elle au cours des âges.

2 Les quelque deux cents pages que comporte le livre de Frédérique Jacquemin nous font cheminer dans l'univers particulier d'une couleur dont Rainer Maria Rilke admirait tant les nuances subtiles et à propos de laquelle il rêvait qu'un auteur, un jour, consacrât une biographie. Le terme utilisé par le poète autrichien est précieux: le bleu est bien une matière vivante à laquelle il convient de porter attention. Mieux, il lui apparaît comme un être singulier et, à ce titre, passible d'une biographie. C'est donc ce défi que l'auteur va relever et qui va l'amener à construire son synopsis. Au fil de la vingtaine de courts chapitres qui lui est consacré, le bleu apparaît dans sa troublante diversité. Il trouve dans le fard à paupière de Cléopâtre, les vitraux des églises ou la toile des peintres les moyens de son plus complet rayonnement. Ses vertus, ses secrets, ses infortunes jalonnent une histoire où les actions guerrières - celles qu'engagent les marchands de garance et de guède- relativisent l'angélisme auquel Matisse aimait associer cette couleur. Le bleu outremer sanctifie les Vierges de l'Angelico, mais devenu indigo, il marque l'histoire américaine du sceau funeste de l'esclavage. L'analyse de Frédérique Jacquemin repose, on le voit, autant sur les exemples pris dans l'histoire de l'art que dans l'histoire tout court. C'est là son mérite principal. L'analyse ouvre sur des propositions intéressantes mais, à 
l'instar de l'avant-propos et de la petite anthologie poétique qui ouvrent le livre, le corps du texte se présente comme un échantillonnage qui peut laisser sur sa faim un lecteur plus attentif et exigeant. Les œuvres aux légendes lacunaires figurent dans une liste peu utilisable, comme l'est aussi malheureusement l'index des noms cités sans pagination. Malgré ces défauts, l'ouvrage, dans l'objectif qui est le sien, reste attachant et offre un parcours doté d'une iconographie abondante et intéressante.

Bleu: histoire d'une couleur, de l'historien Michel Pastoureau, est une étude à la fois très structurée et très informée. Le plan en est clair et l'écriture concise. D'emblée, l'auteur nous amène à appréhender la couleur -le bleu, en l'occurrence- dans une perspective nettement historique, et non pas, comme trop fréquemment, dans une visée purement neurobiologique. Construction culturelle plus que phénomène naturel, fait de société plus que vérité transculturelle, la couleur appartient à l'histoire sociale et le bleu, comme les autres, est objet de règlements et d'enjeux dont l'auteur va s'employer, tout au long de sa belle étude, à rendre compte. Fondée sur des documents de toute nature -non limités au champ pictural ou artistique - l'analyse de Michel Pastoureau sur la couleur en question fait état de l'évolution du langage qui lui est attaché, de celle des goûts et des modes qui, parfois, apparaissent comme de véritables phénomènes de moralisation. L'usage du bleu peut, en effet, selon les périodes, être aussi bien le symbole de la barbarie que celui de la civilisation la plus raffinée. Son émergence est, du reste, fort longue. Le vêtement comme l'iconographie ignoreront longtemps sa valeur et plus encore sa beauté. Nul durant la période préhistorique, à l'exception notable de l'Egypte, son usage reste faible chez les romains. Absent chez les liturgistes et peu goûté dans le haut Moyen Age, le bleu resplendira un jour enfin dans les imposantes verrières du Gothique. L'abbé Suger lui apporte son soutien et, au nom de la foi lumineuse, favorise sa promotion, malgré les choix chromophobes de Clairvaux. Dès lors, le bleu entre dans les images comme dans les mœurs. La juste et pertinente iconographie proposée dans l'ouvrage nous permet de découvrir son essor qui, plus jamais, ne se démentira. Images de la Vierge, annonciations, présentations au temple : toute l'iconographie du culte marial se développe sous le signe du bleu, lequel, au plan économique, connaît aussi une constante valorisation. La guerre des teinturiers du rouge et du bleu peut alors commencer. Elle ne cessera que lorsque les techniques de la teinture seront suffisamment évoluées et que la vogue du bleu sera entièrement assurée. Du bleu attribut royal à celui que le culte, l'art, la mode vestimentaire choisiront bientôt, il y a place pour toutes les pratiques et pour tous les goûts. Le Romantisme l'adoptera avec ferveur tout comme l'ordre politique dont les armoiries, les cocardes, les drapeaux arborent les valeurs nouvelles qu'il entend véhiculer. Surgit alors l'efficace politique et militaire du bleu. La Révolution ne restera pas indifférente à sa force symbolique tout comme l'ensemble des armées qui plus ou moins rapidement adoptera la couleur pour ses vertus protectrices. A cet égard, l'auteur rappelle judicieusement que le retard pris par l'armée française à troquer le pantalon rouge contre le bleu fut, en 1914, à l'origine de considérables hécatombes sur les champs de bataille. Bien avant que le bleu de Prusse n'affronte le "bleu horizon", le jeune Levi Strauss taillait dans la toile bleue de sa tente l'impérial jean. Celui-ci allait bien vite supplanter tous les autres bleus vestimentaires - uniformes, blouses, vêtements de travail - et habiller dorénavant la jeunesse planétaire qui, dans ce curieux conformisme, devait néanmoins trouver le symbole de son émancipation. De Picasso à Klein, en passant par Eluard et Monory, la période bleue ne saurait être celle des seuls artistes, poètes ou musiciens. Le bleu, aujourd'hui plus que jamais, est la couleur du consensus social. Les affiches des campagnes électorales le prennent toutes pour fond tout comme les drapeaux 
sous lesquels se rangent les nations et les pays. C'est à de telles réflexions qu'invite le beau livre de Michel Pastoureau. 